\title{
The Effect of Organization Size and Sector on Adopting Business Process Management
}

\author{
Amy Van Looy $\cdot$ Joachim Van den Bergh
}

Received: 30 November 2015 / Accepted: 28 September 2016/Published online: 17 July 2017

(C) Springer Fachmedien Wiesbaden GmbH 2017

\begin{abstract}
The business process management (BPM) discipline is starting to recognize the importance of contextawareness. In spite of this recognition, few studies investigate the effect of diverse contextual factors on BPM. To fill this gap, the study statistically analyzes the effect of organization size and sector, as specific contextual factors, on the adoption of BPM. The latter is measured by means of BPM capabilities for which data was collected from 2309 employees in 72 organizations. The study relies on the Contingency Theory by hypothesizing that, in practice, organizations adopt BPM by taking into account factors that fit an organization's context. Surprisingly, the results do not show a dependency between BPM adoption and organization size, suggesting that BPM adoption levels can equally be achieved by large or small organizations. In contrast, a dependency is found for organization sector (partly based on market velocity), suggesting different BPM adoption practices and/or speed in different sectors.
\end{abstract}

Keywords BPM maturity - Adoption of BPM - Contextaware BPM - Contingency · Organization size .

Organization sector $\cdot$ Business strategy

Accepted after one revision by Prof. Dr. Becker.

Prof. Dr. A. Van Looy $(\bowtie)$

Department of Business Informatics and Operations

Management, Faculty of Economics and Business

Administration, Ghent University, Tweekerkenstraat 2,

9000 Ghent, Belgium

e-mail: Amy.VanLooy@UGent.be

URL: http://www.amyvanlooy.eu/

J. Van den Bergh

Vlerick Business School, Reep 1, 9000 Ghent, Belgium

e-mail: Joachim.Vandenbergh@ vlerick.com

\section{Introduction}

The business process management (BPM) discipline aims at managing and improving the business processes of an organization to achieve, among others, long-term sustained competitive advantage and compliance for organizations (Hung 2006; Rosemann et al. 2008; Trkman 2010). It does so by combining specific technologies (e.g., designing, automating, and monitoring business processes) and management principles (e.g., organizational structure, leadership styles and cultural readiness) (vom Brocke et al. 2014). For instance, de Bruin and Rosemann (2007) refer to BPM capability areas such as methods and IT, as well as strategic alignment, governance, people, and culture. Similarly, Van Looy et al. (2014) refer to BPM capability areas for process modeling, deployment and optimization, as well as process management and a process-oriented culture and structure.

In response to recent calls for more context-awareness in BPM adoption (vom Brocke et al. 2014), this study approaches the subject by looking at the state of development of BPM capabilities at a certain moment in time in relation to contextual factors such as an organization's size and sector. In particular, context-aware BPM adoption seems to contradict frameworks that offer a generic image of BPM - often based on best practices - and sometimes offering step-by-step roadmaps to increase maturity, such as (de Bruin and Rosemann 2007; McCormack and Johnson 2001; Hammer 2007). Nonetheless, many practitioners use these frameworks and corresponding maturity models for assessing and improving business processes in many different contexts (Harmon 2013). The question is whether maturity models and roadmaps, based on generic best practices, offer a good fit in a discipline that calls for more context-awareness, and thus customized adoption practices. 
Hence, acquiring more knowledge about the relationship between BPM adoption and the organizational context is important.

Since 'context' is a broad concept, a wide variety of contextual factors is likely to exist. Rosemann et al. (2008) define an 'organizational context' with different layers (i.e., an environment, external, internal, and immediate process layer). Our present study considers two contextual factors, i.e., organization size (as a factor in the internal layer of an organization) and organization sector (as a factor in the external layer). The scope is thus limited to stable factors, without examining more dynamic contextual factors (e.g., market competition, commodity prices, weather, etc.). Particularly, we empirically investigate a significant amount of data from organizations and employees, for which organization size and sector are measured in a straight-forward way, enhancing reliability. Moreover, we supplement other empirical studies which address the effect of organizational size and sector on BPM adoption (Hribar and Mendling 2014; Weitlander and Kohlbacher 2015). For instance, while researching the correlation of organizational culture on BPM adoption success, Hribar and Mendling (2014) showed the statistical non-significance of organizational size and sector. On the other hand, the study of Weitlander and Kohlbacher (2015) suggests statistical importance of organization size and sector in the sense that manufacturers are generally more process-oriented than service providers, and that large companies are generally more process-oriented than small ones. An explanation given by these authors is that "manufacturers recognized process management's benefits early on. Meanwhile service providers adopt related practices with slight adaptations as well and even potentials for small and flexible firms have been revealed" (Weitlander and Kohlbacher 2015, p. 44). Weitlander and Kohlbacher (2015) do, however, agree with Hribar and Mendling (2014) that a process-oriented culture seems independent from organization size and sector. The few existing studies that address context-aware BPM adoption take a rather dichotomous view of small versus large organizations, and service versus non-service organizations. Hence, an empirical study is lacking that simultaneously focuses on: (1) BPM adoption in a quantitative way for reasons of generalization, (2) with multiple respondents per organization to reduce subjectivity (Enticott et al. 2009), and (3) by examining organization size and sector from a more refined perspective.

This introductory section has shown that the general importance of context-awareness is increasingly recognized in the business process literature. Yet, more research is needed on specific contextual factors and the extent to which they affect BPM adoption. Our study builds upon the Contingency Theory which states that organizations should adapt themselves to their environment, i.e., be contingent upon their particular operating conditions. Since the Contingency Theory requires a 'fit' with the environment, it assumes that a universal or single 'best' way to conceptualize an organization does not exist (Donaldson 2001; Fiedler 1964; Lawrence and Lorsch 1969; Thompson 1967). Nonetheless, patterns may be uncovered by investigating the effect of particular contextual factors on BPM. Hence, our research question is:

- RQ. To which degree do organization size and sector affect the BPM capability adoption of an organization?

This study thus addresses the search for contextual factors that influence organizational BPM practices. It intends to provide further empirical evidence which helps to look at industry-specific BPM adoption practices, counter sizable prior work that assumes 'one-size-fits-all' approaches to BPM, and move away from a more traditional lifecycle research perspective. In particular, this study contributes to the context-awareness discussion by supplementing other studies that examine different approaches to climb the maturity ladder (i.e., roadmap or growth path). For instance, Bucher and Winter (2010) propose a taxonomy of BPM projects depending on the maturity level of an organization. When reaching higher maturity levels (i.e., after a longer time of BPM adoption), the taxonomy differentiates a custom-made approach from a more standards-based approach. Further, more in-depth research on case-specific critical success factors of BPM programs (Trkman 2010) and on turning points or milestones to move to subsequent maturity levels (McCormack et al. 2009) may help organizations to better prioritize their improvement efforts. By treating context and ideas borrowed from other disciplines in an empirical way, we intend to give our work a fresh perspective on context-aware BPM.

The remainder of the paper is structured as follows. Section 2 provides the theoretical background. The methodology for collecting and analyzing empirical data is explained in Sect. 3. Afterwards, the results are presented in Sect. 4, and discussed in Sect. 5. Section 6 concludes by summarizing the main findings and avenues for future research.

\section{Theoretical Background}

This section motivates our choice for organization size and sector as the subset of contextual factors that may affect an environmental fit, as suggested by the Contingency Theory.

\subsection{Selection of Contextual Factors}

A first motivation for selecting specific contextual factors is found in the need for strategic alignment, which means 
that BPM should serve the organizational mission and strategy, and that the goals of business processes should be aligned with the organizational goals. Three strategic paradigms exist for long-term sustained competitive advantage (Teece et al. 1997): (1) Structure-ConductPerformance paradigm, (2) Strategic Conflict paradigm, and (3) Resource-Based View (RBV) paradigm. Each strategic paradigm emphasizes contextual factors that may impact on the way BPM is approached in specific organizations. From the perspective of the Structure-Conduct-Performance paradigm, organizations should manage and improve business processes (or the internal way of working) to help handle Porter's five competitive forces (2008), i.e., (1) bargaining power of suppliers, (2) bargaining power of customers, (3) threat of substitute products or services, (4) threat of new entrants, and (5) industry rivalry (Miller and Friesen 1986). Within the Strategic Conflict paradigm, doing business is seen through the lens of game theories, and business processes should help create entry barriers, entry deterrence or strategic interaction, e.g., by product differentiation or low unit costs. On the other hand, RBV conceptualizes an organization as a bundle of resources or capabilities (among others BPM capabilities or business processes) to achieve superior performance (Wernerfelt 1984; Rumelt 1984). This paradigm is refined by the Dynamic Capability theory, which distinguishes operational capabilities from dynamic capabilities (Eisenhardt and Martin 2000; Teece et al. 1997; Niehaves et al. 2011). In particular, dynamic capabilities explain why certain organizations are able to maintain their advantage in highly volatile markets characterized by rapid and unpredictable change.

The third paradigm has a stronger focus on the internal organization, and is considered to be complementary to the other two paradigms which represent a more externally focused approach. Hence, according to the definition of 'organizational context' (Rosemann et al. 2008) mentioned in the introduction section, the first two paradigms are more situated in the environmental and external layer, while RBV is rather situated in the internal and immediate process layer.

BPM as a discipline has had a strong internal focus in practice, e.g., by investigating internal business improvements through process mining, modeling, Reengineering, Lean or Six Sigma (Rosemann 2014), clearly linked to the RBV paradigm. However, there is call for a more external focus in future BPM research directions to investigate how BPM capabilities can be strategically adopted (de Oliveira Lacerda et al. 2014; Forrester 2014; Niehaves et al. 2014; Trkman 2010; Rosemann 2014). In this study, we add the external paradigms to the BPM discipline by investigating contextual factors that possibly influence BPM as well. We particularly rely on the Contingency Theory to find a fit between the BPM discipline and an organization's environment (Trkman 2010). The Structure-Conduct-Performance paradigm and the Strategic Conflict paradigm seem to relate to 'market speed' or 'market velocity' as the strategic context in which organizations operate. Similarly, one of the few contingency studies in the BPM discipline also mentions a factor called 'market stability' (Niehaves et al. 2014) as a supplement to the capability framework of Rosemann et al. (2007, 2010). This strategic context will be included in our study by means of the organization sector.

Moreover, organization size and organization sector (i.e., in the sense of market velocity) are recognized factors in context-awareness research of other disciplines. In particular, several review articles on contingency studies state that the sector and size of the organization, team and/or project should be taken into account in disciplines such as operations management (Sousa and Voss 2008), software process tailoring (Kalus and Kuhrmann 2013; Xu and Ramesh 2007), product development process tailoring (du Preez et al. 2009), and situational method engineering (Bucher et al. 2007).

For reasons of theory development, the next section presents the causal logic that explains why organization size and sector may also affect the BPM discipline.

\subsection{Research Hypotheses}

Our work is theoretically underpinned by the Contingency Theory. The basic paradigm is that organizational performance results from fitting characteristics of the organization to contingencies that reflect its (internal and/or external) environment or context. Because a change in any contingencies is likely to result in a change of corresponding organizational characteristics, the optimal structural level is seldom the maximum but depends on the level of fit with the contingency factors (Burns and Stalker 1961; Child 1975; Lawrence and Lorsch 1969).

Figure 1 summarizes the research model with a Contingency Theory approach for BPM adoption. It shows the two concepts that typify the Contingency Theory, namely "fit" and "performance". We consider the organization size and sector as the independent contextual variables, whereas BPM adoption or the degree to which BPM capabilities have been adopted as the dependent variable.

Lifecycle theories on BPM adoption, which are typically followed by traditional BPM maturity models such as (de Bruin and Rosemann 2007; McCormack and Johnson 2001; Hammer 2007), assume that higher maturity eventually leads to higher operational performance, while lower BPM maturity relates to lower financial and non-financial performance (Skrinjar et al. 2008). In contrast, the 
Fig. 1 The research model of the present study

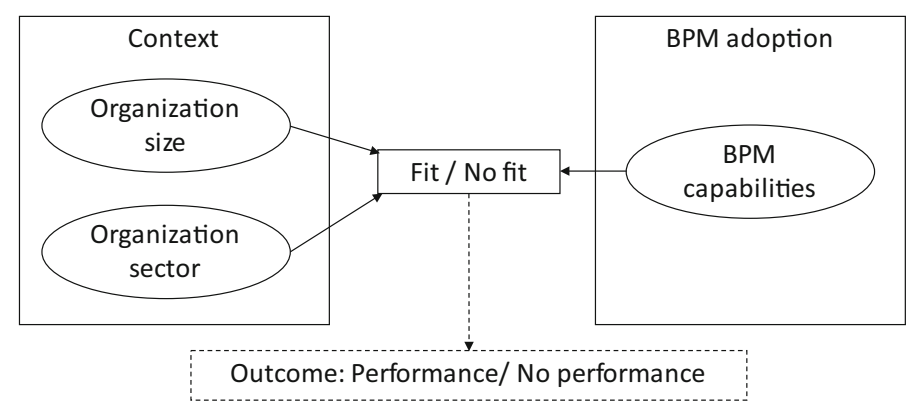

\subsection{Operationalization}

BPM adoption is typically measured by maturity models and capability frameworks. For the present article, the operationalization of BPM adoption is based on the model of Willaert et al. (2007), which was previously validated by means of a profound literature study, the authors' experience and information obtained from interviews with experts and practitioners. This model measures the whole process portfolio in an organization, without focusing on specific business processes. It is based on maturity models such as (McCormack and Johnson 2001; Hammer 2007), which typically measure how broad BPM is adopted in a particular organization or business process (i.e., by measuring different capabilities) as well as how deep BPM is adopted (i.e., by calculating a degree per capability and/or among capabilities). Moreover, the model that we apply for this article can also be called holistic in the sense that it covers all main capabilities in recognized capability frameworks (de Bruin and Rosemann 2007; Van Looy et al. 2014).

Willaert et al. (2007) measure an organization's way of BPM adoption by means of eight capabilities, as shown in Table 1. Based on the data collected, an overall level or adoption score can be calculated by averaging the eight individual capability levels or capability scores. Although other calculation techniques exist (e.g., the lowest value), the average score represents BPM adoption by considering all capabilities involved (i.e., instead of focusing on the weakest capability) and this with equal weights among organizations to facilitate inter-organizational comparisons.

We will apply this overall level or score as an indicator for "BPM capability adoption" in order to find patterns or groups characterized by a similar adoption rather than focusing on the degree (low/medium/high).

\subsection{Data Collection}

We had access to a dataset with BPM capability adoption scores of 2,531 West-European employees, which were collected between 2006 and 2011. Previously, this dataset 
Table 1 The operationalization of capabilities by Willaert et al. (2007)

\begin{tabular}{|c|c|}
\hline Capabilities & Measurement items \\
\hline \multirow{10}{*}{$\begin{array}{l}\text { 1. Customer orientation } \\
\text { (10 items) }\end{array}$} & Customer requirements \\
\hline & Customer satisfaction \\
\hline & Customer feedback \\
\hline & $\begin{array}{l}\text { Customer requirements, mission and } \\
\text { values }\end{array}$ \\
\hline & $\begin{array}{l}\text { Adaption of processes to customer } \\
\text { requirements }\end{array}$ \\
\hline & Communication to customers \\
\hline & Customer complaint tracking \\
\hline & Customer complaint feedback \\
\hline & Case workers \\
\hline & $\begin{array}{l}\text { Customer input for process } \\
\text { improvements }\end{array}$ \\
\hline \multirow[t]{9}{*}{ 2. Process view (9 items) } & $\begin{array}{l}\text { Inputs and outputs to and from } \\
\text { customers }\end{array}$ \\
\hline & Connected activities across departments \\
\hline & Process terminology \\
\hline & $\begin{array}{l}\text { Standard methodology for process } \\
\text { documentation }\end{array}$ \\
\hline & Documentation availability \\
\hline & Employee understanding \\
\hline & $\begin{array}{l}\text { Value of process formalization (recoded } \\
\text { from 'waste of time') }\end{array}$ \\
\hline & $\begin{array}{l}\text { Standard methodology for process } \\
\text { updates }\end{array}$ \\
\hline & Key performance indicators \\
\hline \multirow{8}{*}{$\begin{array}{l}\text { 3. Organizational } \\
\text { structure ( } 8 \text { items })\end{array}$} & Process support across departments \\
\hline & Interdepartmental coordination \\
\hline & Presence of process owners \\
\hline & Take responsibility \\
\hline & Business process office \\
\hline & $\begin{array}{l}\text { Improvement authority of process } \\
\text { owners }\end{array}$ \\
\hline & Process experts and advice \\
\hline & Process outsourcing \\
\hline \multirow{11}{*}{$\begin{array}{l}\text { 4. Process performance } \\
\text { (11 items) }\end{array}$} & Regular performance measurement \\
\hline & Strategic alignment \\
\hline & Performance measurement system \\
\hline & Input resource utilization \\
\hline & Benchmarking \\
\hline & Reporting system \\
\hline & Regular performance communication \\
\hline & Process metrics \\
\hline & Resources allocation \\
\hline & Registration of unexpected events \\
\hline & Process control \\
\hline
\end{tabular}

Table 1 continued

\begin{tabular}{|c|c|}
\hline Capabilities & Measurement items \\
\hline \multirow{10}{*}{$\begin{array}{l}\text { 5. Culture, values and } \\
\text { beliefs (10 items) }\end{array}$} & Interdepartmental tensions (recoded) \\
\hline & $\begin{array}{l}\text { Interdepartmental interactions (recoded } \\
\text { from 'dislike') }\end{array}$ \\
\hline & $\begin{array}{l}\text { Harmony between interdepartmental } \\
\text { goals }\end{array}$ \\
\hline & Protection of departmental turf (recoded) \\
\hline & Top management support \\
\hline & $\begin{array}{l}\text { Interdepartmental meetings between } \\
\text { managers }\end{array}$ \\
\hline & Proactive problem-solving \\
\hline & $\begin{array}{l}\text { Communication procedures between } \\
\text { departments }\end{array}$ \\
\hline & Consulting other departments \\
\hline & Focus on customer \\
\hline \multirow{7}{*}{$\begin{array}{l}\text { 6. People management (7 } \\
\text { items) }\end{array}$} & Teamwork \\
\hline & Training for interdisciplinary work \\
\hline & Team building activities \\
\hline & Training for process improvement \\
\hline & Multidimensional jobs \\
\hline & Managers as coaches \\
\hline & Employee accountability \\
\hline \multirow{6}{*}{$\begin{array}{l}\text { 7. Information technology } \\
\text { (6 items) }\end{array}$} & Integration of processes by IT \\
\hline & Integration of departments by IT \\
\hline & Customer support \\
\hline & Performance support \\
\hline & Management of customer information \\
\hline & Business process management system \\
\hline \multirow{7}{*}{$\begin{array}{l}\text { 8. Supplier perspective (7 } \\
\text { items) }\end{array}$} & Supplier monitoring \\
\hline & Supplier requirements \\
\hline & Supplier input for process improvements \\
\hline & $\begin{array}{l}\text { Shared belief in ongoing process } \\
\text { improvements }\end{array}$ \\
\hline & $\begin{array}{l}\text { Adaption of processes to supplier } \\
\text { requirements }\end{array}$ \\
\hline & $\begin{array}{l}\text { Collaboration for ongoing process } \\
\text { improvements }\end{array}$ \\
\hline & Communication to suppliers \\
\hline
\end{tabular}

was used in a publication to validate the model under study (Willaert et al. 2007) and for reasons of consultancy tasks focusing on employee-level data. Hence, novelty in our applied analysis lies within the inter-organizational comparison (i.e., requiring a novel pre-processing phase) with a focus on size and sector.

For data quality purposes, the dataset was pre-processed as follows. First, we eliminated data on the employee-level if one or more of the following conditions was true: 
- Survey was not completed.

- Survey was completed within less than 5 min.

- Survey was completed with identical answer options for all capability questions.

This first pre-processing stage resulted in 2312 remaining employees belonging to 75 organizations. As advocated by Enticott et al. (2009), multiple informant surveys are generally more accurate than surveying a single respondent per organization. Hence, in a second pre-processing stage, the organization-level was calculated by averaging the BPM capability adoption scores of employees belonging to the same organization. We eliminated data on the organization-level if:

- Survey was completed by only one employee in the organization.

The final dataset contained the BPM capability adoption scores of 2309 employees in 72 organizations.

\subsection{Hypothesis Testing}

The variables under study were initially collected on different measurement levels.

- Organization size: ordinal variable (i.e., with five categories).

- Organization sector: nominal variable (i.e., with 22 categories).

- BPM capability adoption: scale variable (i.e., as a decimal ranging from 1 to 7 ).

As the organization size and sector are categorical variables, we decided to supplement categorical statistics with scale statistics to enhance the credibility of the results (SPSS, version 22; R, version 3.2.2).

A multivariate statistical analysis with categorical data typically starts with cross tabulations (i.e., contingency tables). Based on this output, a statistic can be calculated to investigate whether dependencies between the categorical variables are likely to exist. Given that the total sample size is 72 and the expected cell values are likely to be less than five, we decided not to apply the Pearson's Chi square or $G$-tests in order to increase validity. Instead, we can opt for the Fisher's exact test of independence for $2 \times 2$ tables, and alternatively the R package "coin" based on 9999 Monte-Carlo resamplings for nxm tables (Hothorn et al. 2008). In other words, for this first type of hypothesis testing, we deliberately did not combine possible sparse categories to allow a more refined view on organization size and sector. Only the BPM capability adoption scores were recoded into an ordinal variable by striving to an equal amount of observations per category, because our intention is to detect different categories of organizations with similar adoption scores rather than to calculate a low, medium and high score.

- BPM capability adoption: ordinal variable (i.e., with four categories)

Furthermore, we performed an additional hypothesis testing based on two-sample inference in order to directly compare our results with previous studies (see Sect. 1). Based on this output, a $t$ test can be calculated to examine whether the BPM capability adoption means of independent random samples of two or more groups are similar. For this second type of hypothesis testing, the initial BPM capability adoption variable was used, while the variables of organization size and sector were recoded.

- Organization size:

- small and medium-sized enterprises versus large organizations.

- Organization sector:

- product organizations versus service organizations.

- private versus public and social profit organizations.

Since organization size and sector are independent of each other (i.e., particular sectors can entail smaller and larger organizations; Monte-Carlo $P=0.395>0.100$ ), we report on two sets of hypotheses, mentioned before.

Only if hypothesis testing suggests a statistically significant dependency concerning one of the hypotheses, an additional multivariate technique is required to investigate the degree of dependence in more detail.

\subsection{Correspondence Analysis}

Correspondence analysis (Benzécri 1992) is an exploratory multivariate statistical technique which examines dependencies or associations between categorical variables based on dimension reduction (i.e., to two-dimensional axes in our study). Therefore, it is especially useful for variables with a large number of categories (e.g., 22 categories for measuring the 'organization sector'). A strength of this technique is that it '(...) results in an elegant but simple graphical display which permits more rapid interpretation and understanding of the data' (Greenacre 2007, p. ix). For this purpose, correspondence analysis allows to visualize patterns in categorical data by means of dominant points, similar to a scatterplot with a horizontal $\mathrm{x}$-axis and a vertical $\mathrm{y}$-axis. Besides the need for categorical data, some pragmatic guidelines for conducting a correspondence analysis are related to the total inertia (i.e., spread) explained by the different dimensions: (1) the first dimension should not explain more than $90 \%$ of the total inertia (i.e., otherwise a single dimension would suffice), (2), the first two dimensions 
should explain about $85-90 \%$ of the total inertia, and (3) a third dimension would not explain much more of the total inertia. The resulting plot gives the reader insight into the relationship between two or more categorical variables based on similar distributions, e.g., whether values of a variable on one axis correspond with values of the other variable on the same axis.

\section{Results}

\subsection{Hypothesis Testing for Organization Size}

\subsubsection{Organization Size with Five Categories}

We first report on the hypothesis testing results for organization size. The cross tabulation of organization size by BPM capability adoption is shown in Table 2 . The related Monte-Carlo $P$-value indicates that the null hypothesis $\left(\mathrm{H}_{0}\right)$ cannot be rejected $(P=0.946>0.100)$. Hence, the organization size and BPM adoption appear to be independent in our dataset.

In addition, different nominal and ordinal association measures agree that a correlation between organization size and BPM capability adoption is statistically not significant $(P>0.100)$.

\subsubsection{SMEs versus Large Organizations}

In order to follow the dichotomous view of previous studies (see Sect. 1), we also distributed our dataset in two samples that distinguish small and medium-sized enterprises (SMEs) from large organizations. The initial variable for organization size was therefore recoded conform to the European SME definition (i.e., equal or below 250 employees versus more than 250 employees). The additional hypothesis testing (i.e., $t$-test) concerns two-sample inference. For this data, we first check the assumptions of parametric tests, i.e., (1) the assumption of normality of distributions, and (2) the assumption of homogeneity of variance.

Regarding the normality assumption, descriptive statistics and the tests of normality suggest that the distribution of BPM adoption observations does not deviate dramatically from a normal distribution. Particularly, the probability $(P)$ that the deviations from a normal distribution can be attributed to the randomness of the observations is large for the Kolmogorov-Smirnov test (i.e., at least 20\%) as well as for the Shapiro-Wilk's test (i.e., about 98 and $37 \%$ for SMEs and large organizations, respectively).

Secondly, to test whether the variances in both populations can be considered as equal, the Levene's test is based on the absolute deviations of the observations to the mathematical BPM adoption mean in each group. The $P$ value resulting from this test is given by $\mathrm{Sig} .=0.981$, which means that we do not reject the assumption of equality of variances in both populations. Hence, we can proceed with the $t$-test for means of two independent samples having equal variances.

Under the assumptions of normality and equal variances, the probability of exceeding the absolute value of $t_{\mathrm{s}}=-0.198$ is given by Sig.(2-tailed) $=0.843$. This is the probability that an absolute difference in the sample means, at least at large as -0.0244 , will be observed if the samples are drawn from populations that have identical location. Since this probability is larger than 0.050 or 0.100 , we can conclude that the observed difference in BPM adoption between SMEs and large organizations, in favor of the last one, is statistically not significant. In other words, BPM adoption on the average is expected to be similar for SMEs and large organizations (mean $=4.433$, s.d. $=0.344$, s.e.m. $=0.041, \mathrm{n}=72)($ two-sided $t$-test,$P>0.100)$.

\subsection{Hypothesis Testing for Organization Sector}

\subsubsection{Organization Sector with 22 Categories}

Secondly, we discuss the hypothesis testing results for organization sector. The cross tabulation of organization
Table 2 The cross tabulation of organization size by BPM capability adoption

\begin{tabular}{lccccc}
\hline & \multicolumn{2}{l}{ BPM capability adoption } & Total \\
\cline { 2 - 5 } & $\leq 4.25$ & $4.25<\mathrm{x} \leq 4.50$ & $4.50<\mathrm{x} \leq 4.75$ & $>4.75$ & \\
\hline Organization size & 1 & 2 & & & \\
Fewer than 100 & 2 & 1 & 1 & 1 & 4 \\
Between 101 and 250 & 7 & 5 & 3 & 3 & 5 \\
Between 251 and 1000 & 5 & 8 & 7 & 5 & 25 \\
Between 1001 and 5000 & 5 & 6 & 7 & 2 & 20 \\
More than 5000 & 20 & 22 & 18 & 12 & 72 \\
Total & & & & 1 & 5 \\
\hline
\end{tabular}


Table 3 The cross tabulation of organization sector by BPM capability adoption

\begin{tabular}{|c|c|c|c|c|c|}
\hline & \multicolumn{4}{|c|}{ BPM capability adoption } & \multirow[t]{2}{*}{ Total } \\
\hline & $\leq 4.25$ & $4.25<\mathrm{x} \leq 4.50$ & $4.50<\mathrm{x} \leq 4.75$ & $>4.75$ & \\
\hline \multicolumn{6}{|l|}{ Organization sector } \\
\hline Automotive service & 0 & 0 & 0 & 1 & 1 \\
\hline Banking, finance and accounting & 1 & 5 & 7 & 1 & 14 \\
\hline Consulting & 0 & 1 & 1 & 1 & 3 \\
\hline Education and research & 0 & 0 & 1 & 0 & 1 \\
\hline Government and public sector & 3 & 0 & 0 & 0 & 3 \\
\hline Healthcare & 2 & 0 & 3 & 0 & 5 \\
\hline Human resources services & 0 & 3 & 1 & 0 & 4 \\
\hline ICT services & 3 & 4 & 0 & 1 & 8 \\
\hline Manufacturing (chemicals) & 0 & 0 & 0 & 1 & 1 \\
\hline Manufacturing (construction materials) & 1 & 0 & 0 & 0 & 1 \\
\hline Manufacturing (electro devices) & 1 & 1 & 0 & 2 & 4 \\
\hline Manufacturing (food and drinks) & 0 & 0 & 0 & 1 & 1 \\
\hline Manufacturing (industrial textiles) & 1 & 0 & 0 & 0 & 1 \\
\hline Manufacturing (laboratory equipment) & 0 & 1 & 0 & 0 & 1 \\
\hline Manufacturing (mining minerals) & 0 & 0 & 1 & 0 & 1 \\
\hline Manufacturing (pharmaceuticals) & 0 & 1 & 0 & 2 & 3 \\
\hline Media & 1 & 0 & 0 & 0 & 1 \\
\hline Public transport & 2 & 0 & 0 & 0 & 2 \\
\hline Retail & 2 & 2 & 1 & 0 & 5 \\
\hline Telecommunication & 1 & 2 & 1 & 1 & 5 \\
\hline Tourism & 1 & 0 & 0 & 0 & 1 \\
\hline Utilities & 1 & 2 & 2 & 1 & 6 \\
\hline Total & 20 & 22 & 18 & 12 & 72 \\
\hline
\end{tabular}

sector by BPM capability adoption is shown in Table 3. The null hypothesis $\left(\mathrm{H}_{0}\right)$ can be rejected, and the alternative hypothesis $\left(\mathrm{H}_{\mathrm{a}}\right)$ accepted $(0.05>$ Monte-Carlo $P=0.028>0.001)$. Hence, BPM adoption seems to significantly differ among the organization sectors in our dataset. The degree of dependence is further investigated by a correspondence analysis in Sect. 4.3.

In addition, different nominal association measures agree that an association between organization sector and BPM adoption is statistically significant $(P<0.100)$.

\subsubsection{Product versus Service Organizations}

For reasons of group comparison, we also categorized the organizations in two groups (i.e., product organizations and service organizations). Again, we first check: (1) the assumption of normality of distributions, and (2) the assumption of homogeneity of variance.

Regarding the assumption of normality, the descriptive statistics and the tests of normality give evidence for normality. In particular, the Kolmogorov-Smirnov tests are statistically not significant (i.e., $P=0.200>0.010$ ) and also the Shapiro-Wilk tests are statistically not significant (i.e., for product organizations: $P=0.486>0.010$; for service organizations: $P=0.110>0.010$ ).

Secondly, we check with the $F$-test whether the adoption variable has equal spread in both populations. The $P$-value associated with $F=1.489$ is larger than 0.050 or 0.100 $($ Sig. $=0.226)$. Hence, we perform the $t$-test assuming equality of variances.

The test statistic is $t_{\mathrm{s}}=0.742$. The approximate degrees of freedom are computed, $d f=70$. The accompanying $P$ value is given as 0.461 , which is larger than 0.050 or 0.100 . From this sample data, we can conclude that the observed difference in BPM adoption between product organizations and service organizations, in favor of the first one, is statistically not significant. Thus, BPM adoption on the average is expected to be similar for product and service organizations $\quad($ mean $=4.433, \quad$ s.d. $=0.344$, s.e.m. $=0.041, \mathrm{n}=72$ ) (two-sided $t$-test, $P>0.050$ ).

\subsubsection{Private versus Public and Social Profit Organizations}

A final group comparison was performed for private organizations, and public and social profit organizations. The data suggests a symmetric distribution for the groups 


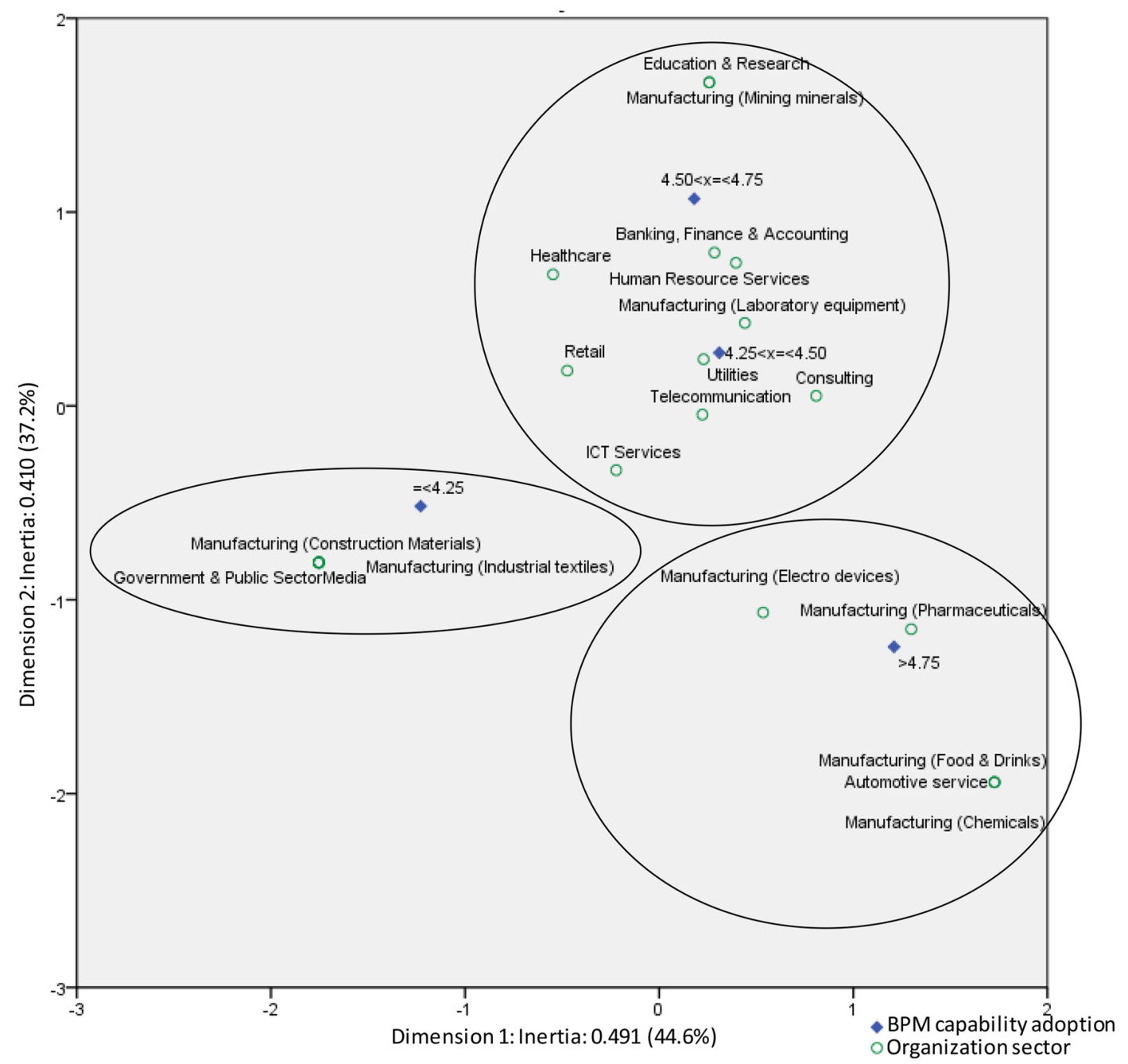

Fig. 2 Symmetric plot of correspondence analysis between organization sector and BPM capability adoption $($ Total inertia $=1.102)$

under study, with statistically non-significant KolmogorovSmirnov tests (i.e., $P=0.200>0.010$ ) and statistically non-significant Shapiro-Wilk tests (i.e., for private organizations: $P=0.220>0.010$; for public and social profit organizations: $P=0.997>0.010$ ).

Further, the $F$-test is statistically not significant $(P=0.201>0.100)$. This implies that the corresponding $t$-test can be interpreted with equal variances assumed. We conclude that BPM adoption on the average is expected to be higher for private organizations (mean $=4.471$, s.d. $=0.321$, s.e.m. $=0.042, \mathrm{n}=58)$ than for public and social profit organizations $($ mean $=4.274$, s.d. $=0.399$, s.e.m. $=0.107, \mathrm{n}=14)($ two-sided $t$-test, $P<0.050)$.

\subsection{Correspondence Analysis for Organization Sector}

Since the hypothesis testing in the previous section suggests a dependency for organization sector (and not for organization size), this study reports on one correspondence analysis.

The symmetric plot of correspondence analysis between organization sector and BPM capability adoption is shown in Fig. 2. The plot consists of two dimensions and approximates the pragmatic guidelines mentioned in the methodology section. Particularly, the first dimension explains $44.6 \%$ of the total inertia (i.e., spread), which is lower than $90 \%$. The two dimensions together explain $81.8 \%$ of the total inertia, which is close to the proposed $85 \%$. Hence, the choice for two dimensions (instead of three dimensions which explain $100 \%$ of the total inertia) seems justified.

Figure 2 visualizes three groups or patterns in the data. On the left, it is shown that the dominant points for BPM capability adoption scores lower than or equal to 4.25 generally correspond with the dominant points in sectors such as 'Government and Public Sector', 'Media', 
Table 4 Overview of the research results

\begin{tabular}{|c|c|c|}
\hline Test & Concretization & Result \\
\hline \multirow[t]{2}{*}{ Organization size by BPM capability adoption } & 5 sizes & $\begin{array}{l}\text { Independent (i.e., similar BPM } \\
\text { adoption) }\end{array}$ \\
\hline & SMEs versus large organizations & $\begin{array}{l}\text { Independent (i.e., similar BPM } \\
\text { adoption) }\end{array}$ \\
\hline \multirow[t]{3}{*}{$\begin{array}{l}\text { Organization sector by BPM capability } \\
\text { adoption }\end{array}$} & 22 sectors & $\begin{array}{l}\text { Dependent (i.e., different BPM } \\
\text { adoption) }\end{array}$ \\
\hline & Product versus service organizations & $\begin{array}{l}\text { Independent (i.e., similar BPM } \\
\text { adoption) }\end{array}$ \\
\hline & $\begin{array}{l}\text { Private versus public and social profit } \\
\text { organizations }\end{array}$ & $\begin{array}{l}\text { Dependent (i.e., different BPM } \\
\text { adoption) }\end{array}$ \\
\hline
\end{tabular}

'Manufacturing of construction materials', and 'Manufacturing of industrial textiles'. On the right of Fig. 2, the dominant points for BPM capability adoption scores higher than 4.75 (i.e., >4.75) generally correspond with the dominant points in sectors such as 'Manufacturing chemicals', 'Automotive service', 'Manufacturing food and drinks', 'Manufacturing pharmaceuticals', 'Manufacturing electro devices'.

In order to find additional evidence supporting our correspondence analysis, a linear regression was conducted with BPM adoption as a dependent scale variable and the 22 organization sectors recoded as dummies (yes/no). The resulting regression equation, limited to the statistically significant sectors $(P<0.100)$, is as follows: " $\boldsymbol{B P M}$ adoption $=4.514+0.367^{*} \quad$ (Automotive Service $)+0.177 *$ (Manufacturing Chemicals) $-0.335 *$ (Government \& Public Sector) - $0.173 *$ (Manufacturing Industrial Textiles) $-0.315 *$ (Media) $-0.221 *$ (Public Transport) $-0.237 *$ (Retail)". Although the share of variable explained is relatively high (i.e., as expressed by an adjusted $\mathrm{R}^{2}$ of 0.409 or $40.9 \%$ ), the estimates of coefficients are derived from a relatively small sample $(n=72)$. Therefore, it is more interesting to look at the sectors included in the equation than to the slope estimates. This linear regression equation includes those sectors on the right and the left of Fig. 2, which confirms the findings of our correspondence analysis in a non-categorical way.

\section{Discussion}

Substantial information about the BPM capability adoption of 72 organizations was obtained from 2309 employees. The adoption scores in our dataset can thus be trusted in an inter-organizational comparison (Enticott et al. 2009). The large number of respondents per organization also explains why the calculated BPM capability adoption scores (based on averages) do not show drastic differences on a 7-point scale. In particular, under- or overestimations were evened out, resulting in a range of observed BPM capability adoption scores from 3.594 to 5.584 (with a mean of 4.433 and a standard deviation of 0.344 ). Our research results are summarized in Table 4.

\subsection{Discussion for Organization Size}

Regarding organization size, the data suggests that also smaller organizations are able to reach higher BPM capability adoption scores. For instance, the highest category of the adoption variable (i.e., $>4.75$ ) contained at least one observation in each category of the variable "organization size', and involving two SMEs (i.e., "Organization ABC" and "Organization XYZ"). As a result, BPM adoption seems independent of the organization size (i.e., the null hypothesis could not be rejected). This finding, however, contrasts with contingency research in other disciplines, as discussed in Sect. 2. A possible explanation is that SMEs can also benefit from BPM and its typical capabilities, that their BPM adoption is similar to larger-sized organizations, and can be measured with the same model as for larger organizations, allowing benchmarking even along different organization sizes.

For instance, the two SMEs with higher BPM adoption are local consultancy or professional service firms. In particular, the organization with fewer than 100 employees ("Organization ABC") is operational in financial management services, while the organization between 101 and 250 employees ("Organization XYZ") is a legal advisor. Both SMEs have a project-based way of working with highly formalized business processes, little bureaucracy and a strong project methodology. Both are lean process organizations with little overhead. They profit from the flexibility of SMEs, which are typically characterized by fewer silos or hierarchical levels than larger organizations (Wong and Aspinwall 2004). The context or market conditions under which "Organization ABC" and "Organization XYZ" operate seem to play an important role. In particular, in contrast to other SMEs (Wong and Aspinwall 
2004), "Organization ABC" and "Organization XYZ" build more on efficiency than reputation. Without such a strong call for efficiency, an SME may rely more on tacit or implicit knowledge, and experience more challenges to explicitly formalize their business processes compared to larger organizations.

Hence, counter-evidence was found for the classic assumption that SMEs do not actively follow BPM, do not need BPM or are even unable to adopt BPM given their limited resources. Our study also shows that SMEs progressed compared to older studies (Smart et al. 2004). Instead, other factors are likely to be more informative than the organization size, such as the standardization levels of products and services, organization culture or market competitiveness. The latter was investigated in our research by means of the organization sector.

\subsection{Discussion for Organization Sector}

BPM adoption significantly differed among organization sectors, suggesting a dependency (i.e., the null hypothesis could be rejected). Therefore, we take a closer look at the three groups or patterns visualized by the correspondence analysis.

First, each group shows sectors characterized by both products and services. Nonetheless, the group with the highest BPM adoption mainly corresponds to product-related sectors (except for the sector 'Automotive service').

Furthermore, the group with the highest BPM adoption scores does not correspond with organizations in the public sector nor the social profit sector. The public sector appears to be predominant in the group with the relative lower BPM adoption scores, while the social profit sector also corresponds with the group of intermediate BPM adoption scores. The private sector is present in all groups. These observations suggest different levels for BPM adoption in different organization sectors, confirming our hypothesis that 'organization sector' as a contextual factor seems to influence the degree to which BPM is adopted.

Next, our dataset also contains questions about strategy types that may lead to market leadership (i.e., product leadership, customer intimacy or operational excellence) (Treacy and Wiersema 1993), to assign one type to a specific organization. These questions were not included in the statistical analysis, because they were not yet present in the pre-2007 survey. Nonetheless, after a calculation of the post-2007 surveys, the three strategy types can be found for organizations in sectors that correspond with the groups of highest and lowest BPM adoption scores, and can thus not be used to explain the observed difference in BPM adoption. This suggests that BPM is useful as a strategy execution discipline regardless of the chosen strategic value discipline.
Finally, the group with the highest BPM adoption scores corresponds with some sectors that Eisenhardt and Martin (2000) use to describe moderately dynamic or moderatevelocity markets. For instance, the chemical and pharmaceutical organizations in our study are indeed characterized by a context of higher competitiveness and uncertainty compared to the other organizations, particularly those in construction materials, industrial textiles and government. Hence, market velocity (or the degree of changing economic environments) may explain the correspondence analysis to some extent as well.

In sum, we agree with the findings of (Weitlander and Kohlbacher 2015, p. 44), mentioned in the introduction section, that product organizations are generally characterized by an early adoption of BPM compared to most service organizations and SMEs. However, the latter are strongly catching up. Therefore, our study adds two refinements. First, we add the impact of market velocity to previous findings. Secondly, besides (private) product and service organizations, we investigated a considerable amount of public and social-profit organizations, which are generally still lagging behind. Consequently, our statistical findings result in a more refined view on BPM adoption, in which private organizations generally have higher BPM capability adoption scores than social-profit organizations, followed by public organizations. To some extent, this (temporary) phenomenon can be explained by market velocity. For instance, most private product organizations have had an earlier adoption of BPM frameworks due to higher efficiency needs and competition (Tregear and Jenkins 2007), and therefore have gained more opportunities to gradually adopt more BPM capabilities. Private service organizations were initially rather quality players than efficiency players, and they experienced the impact of market velocity later on. On the other hand, public organizations and also many social-profit organizations are less characterized by market pressure and competitiveness, and only experienced the need for more efficiency relatively recently (i.e., in the twenty-first century) (Tregear and Jenkins 2007). This refined view on BPM adoption illustrates the importance of context-awareness, and calls for more context-aware research on market velocity, among others.

\section{Conclusion}

This article focused on the impact of context-awareness in the BPM discipline, and therefore explored the effect of organization size and sector on BPM adoption. It is based on the Contingency Theory which assumes that one generic 'best' way to conceptualize an organization is not likely to exist. The hypotheses derived from this theory propose that 
a significantly different BPM adoption can be expected for organizations operating in distinctive contexts. The choice for organization size and sector as contextual factors in this study was determined by strategic paradigms and contingency studies in other disciplines. The hypotheses were statistically tested on a large dataset by means of multivariate statistics and correspondence analysis. The results showed only partial support for the hypotheses. In particular, it turned out that the organization sector seems to affect the BPM capability adoption of an organization, whereas a dependency could not be found for organization size. A possible explanation for the rejection of organization size is that SMEs may also benefit from BPM and its typical capabilities, and that their BPM adoption degree can be measured with the same maturity model as for larger organizations, allowing benchmarking.

On the other hand, regarding organization sector, organizations with significantly higher BPM capability adoption scores were situated in the private sector, and were potentially characterized by a higher market velocity. Additionally, such organizations might have started earlier with a process-oriented way of working than, for instance, public organizations, resulting in more experience with BPM adoption. Evidence for a significant difference between product-related and service-related organizations could not be found, neither for the choice of one or another strategy (i.e., product leadership, customer intimacy, or operational excellence), which suggests that BPM may help execute different strategies.

In sum, the research has given statistical evidence for the importance of context-awareness in the BPM discipline by suggesting different approaches to adopt BPM (e.g., early start due to market velocity). Nonetheless, more research is needed to investigate the optimal BPM capability adoption for a specific organization based on a set of contextual factors and including performance measures to truly differentiate contingency from the pace of BPM adoption (i.e., whether some sectors just began investing in BPM later and are therefore still on their journey of adopting). Potential avenues for future research could deal with: (1) other contextual factors, (2) other datasets, (3) multiple cases to uncover a typology of context-aware BPM approaches with different procedures or steps for adopting BPM, and (4) insights into the usefulness of generic maturity models and roadmaps compared to context-aware models and roadmaps.

\section{References}

Benzécri JP (1992) Correspondence analysis handbook. Marcel Dekker, New York
Bucher T, Winter R (2010) Taxonomy of business process management approaches. In: vom Brocke J, Rosemann M (eds) Handbook on business process management, vol 2. Springer, Heidelberg, pp 93-114

Bucher T, Klesse M, Kurpjuweit S, Winter R (2007) Situational method engineering. In: Ralyte J, Brinkkemper S, HendersonSellers B (eds) Situational method engineering. Fundamentals and experiences. IFIP, vol 244. Springer, Boston, pp 33-48

Burns T, Stalker GM (1961) The management of innovation. Tavistock, London

Child J (1975) Managerial and organizationsl factors associated with company performance - part II. A contingency analysis. J Manag Stud 12(1-2):12-27

de Bruin T, Rosemann M (2007) Using the Delphi technique to identify BPM capability areas. In: Proceedings of the 18th Australasian conference on information systems. AIS Electronic Library, Toowoomba, pp 642-653

de Oliveira Lacerda RT, Ensslin L, Ensslin SR, Dutra A (2014) A constructiveist approach to manage business process as a dynamic capability. Knowl Process Manag 21(1):54-66

Donaldson L (2001) The contingency theory of organizations. Sage, Thousand Oaks

du Preez N, Lutters D, Nieberding H (2009) Tailoring the development process according to the context of the project. CIRP J Manuf Sci Technol 1(3):191-198

Eisenhardt KM, Martin JA (2000) Dynamic capabilities: what are they? Strateg Manag J 21(10-11):1105-1121

Enticott G, Boyne GA, Walker R (2009) The use of multiple informants in public administration research: data aggregation using organizational echelons. J Public Adm Res Theory 19(2):229-253. doi:10.1093/jopart/mun017

Fiedler F (1964) A contingency-model of leadership effectiveness. Adv Exp Soc Psychol 1:149-190

Forrester (2014) Predictions 2015: the age of the customer is set to disrupt the BPM market. https://www.forrester.com/Predic tions $+2015+$ The + Age + Of + The + Customer + Is + Set + To + Dis rupt+The+BPM+Market/fulltext/-/E-RES120013. Accessed 8 Jun 2015

Greenacre M (2007) Correspondence analysis in practice. Chapman \& Hall/CRC, Boca Raton

Hammer M (2007) The process audit. Harv Bus Rev 85(4):111-123

Harmon P (2013) Case studies in how organizations become more mature. http://www.bptrends.com/bpt/wp-content/publication files/advisor20130611.pdf. Accessed 25 Nov 2015

Hothorn T, Hornik K, van de Wiel M, Zeileis A (2008). Coin: a computational framework for conditional inference. http://finzi. psych.upenn.edu/R/library/coin/doc/coin.pdf. Accessed 5 Nov 2015

Hribar B, Mendling J (2014). The correlation of organisational culture and success of BPM adoption. In: ECIS2014 Proceedings, Tel Aviv. AISEL Library

Hung RY-Y (2006) Business process management as competitive advantage: a review and empirical study. Total Qual Manag Amp Bus Excell 17:21-40

Kalus G, Kuhrmann M (2013) Criteria for software process tailoring: a systematic review. In: Proceedings of the 2013 international conference on software and system process. ACM Digital Library, New York, pp 171-180

Lawrence PR, Lorsch JW (1969) Organization and environment: managing differentiation and integration. Irwin, Homewood

McCormack K, Johnson WC (2001) Business process orientation: gaining the e-business competitive advantage. Lucie Press, St

McCormack K, Willems J, Van den Bergh J, Deschoolmeester D, Willaert P, Stemberger MI, Skrinjar R, Trkman P, Ladeira MB, de Oliveira MPV, Bosilj V, Vlahovic VN (2009) A global 
investigation of key turning points in business process maturity. Bus Process Manag J 15(5):792-815

Miller D, Friesen PH (1986) Porter's (1980) generic strategies and performance: an empirical examination with American data part I: testing Porter. Organ Stud 7:37-55

Niehaves B, Plattfaut R, Sarker S (2011) Understanding dynamic IS capabilities for effective process change: a theoretical framework and an empirical application. In: Proceedings of the 32nd international conference on information systems. AIS Electronic Library, Shanghai, pp 1-11

Niehaves B, Poeppelbuss J, Plattfaut R, Becker J (2014) BPM capability development - a matter of contingencies. Bus Process Manag J 20(1):90-106

Porter ME (2008) The five competitive forces that shape strategy. Harv Bus Rev 86(1):78-93

Rosemann M (2014) Proposals for future BPM research directions. In: Ouyang C, Jung J-Y (eds) Asia Pacific business process management (LNBIP 181). Springer, Heidelberg, pp 1-15

Rosemann M, vom Brocke J (2010) The six core elements of business process management. In: vom Brocke J, Rosemann M (eds) Handbook on business process management, vol 1. Springer, Heidelberg, pp 107-122

Rosemann M, Recker J, Flender C (2008) Contextualization of business processes. Int J Bus Process Integr Manag 3(1):47-60

Rumelt RP (1984) Towards a strategic theory of the firm. Alternative theories of the firm. Compet Strateg Manag 1984:556-570

Skrinjar R, Bosilj-Vuksic V, Stemberger MI (2008) The impact of business process orientation on financial and non-financial performance. Bus Process Manag J 14(5):738-754

Smart PA, Maull RS, Childe SJ, Radnor ZJ (2004) Capitalizing on thematic initiatives: a framework for process-based change in SMEs. Prod Plan Control 15(1):2-12

Sousa R, Voss CA (2008) Contingency research in operations management practices. J Oper Manag 26(6):697-713
Teece DJ, Pisano G, Shuen A (1997) Dynamic capabilities and strategic management. Strateg Manag J 18:509-533

Thompson JD (1967) Organizations in action: social science bases of administrative theory. McGraw-Hill, New York

Treacy M, Wiersema F (1993) Customer intimacy and other value disciplines. Harv Bus Rev 71(1):84-93

Tregear R, Jenkins T (2007) Government process management. http:// www.bptrends.com/publicationfiles/10-07-ART-Govt.ProcessMgt.Tregear\%20and\%20Jenkins-ph.pdf. Accessed 25 Nov 2015

Trkman P (2010) The critical success factors of business process management. Int J Inf Manag 30:125-134

Van Looy A, De Backer M, Poels G (2014) A conceptual framework and classification of capability areas for business process maturity. Enterp Inf Syst 8(2):188-224

vom Brocke J, Schmiedel T, Recker J, Trkman P, Mertens W, Viaene S (2014) Ten principles of good business process management. Bus Process Manag J 20(4):530-548

Weitlander D, Kohlbacher M (2015) Process management practices: organizational (dis-)similarities. Serv Ind J 35(1-2):44-61

Wernerfelt B (1984) A resource-based view of the firm. Strateg Manag J 5:171-180

Willaert P, Van den Bergh J, Willems J, Deschoolmeester D (2007) The process-oriented organization: a holistic view. Developing a framework for business process orientation maturity. In: Alonso G, Dadam P, Rosemann M (eds) 5th international BPM conference. Springer, Heidelberg, pp 1-15

Wong KY, Aspinwall E (2004) Characterizing knowledge management in the small business environment. J Knowl Manag $8(3): 44-61$

Xu P, Ramesh B (2007) Software process tailoring: an empirical investigation. J Manag Inf Syst 24(2):293-328 